\title{
Research on the Application of Passive Energy-Saving Technology in the Reconstruction of Existing Buildings
}

\author{
Gao Ming \\ School of Civil Engineering and Atchitecture, Southwest University of Science and \\ Technology,Mianyang, 621010,Mianyang, China \\ Gm7161@163.com
}

Keywords: Reconstruction of existing buildings, Passive energy-saving technology, Ecology

\begin{abstract}
This paper puts forward the necessity of active adoption of passive energy saving technology in buildingreconstruction in our country firstly, and then combining practical projects, and the ecological reconstruction theory of Existing Buildings, analyzes and concludes five commonly used passive energy-saving technologies--environment improvement, passive solar power, energy-saving reconstruction of maintenance structure, natural lighting and ventilation and Energy strategy, trying to establish primary methods to apply passive energy-saving technologies to reconstruction of buildings so as to make better use of passive energy-saving technologies in practice.
\end{abstract}

\section{Introduction}

In our country, the number of existing buildings is so large and buildings have problems of high energy consumption, bad internal and external environment. Limited by functions and economic conditions at the beginning of the construction, existing buildings can hardly meet current demands. Many buildings had been pulled down before they reached the expected design life, or been operating under high energy-consuming conditions, which resulted in the waste of energy and resources. Passive technologies can save energy totally through the form of building itself, enclosure structure and structural features in a easy, feasible, low-cost, economical, low-carbon green and effective way, thus it is more in line with the current situation of our country and should be taken into consideration before active energy-saving technology.

The passive energy-saving technology originates from Germany. It refers to the technology that can achieve the goal of saving energy in buildings within the life circle, depending totally on the place, room, structural design and materials of building itself rather than any building service system that consumes energy, and optimizes suitable orientation, heat storage materials and natural ventilation equipment as well as cover devices, and that passively conducts acceptation, directly makes use of renewable resources and strengthens measures of thermal insulation and solar control to improve the acclimatization of buildings to local climate and natural environment and reduce energy consumption .

\section{The strategy of passive Eco-fitness technology}

\subsection{The strategy of environment improvement}

Remnant features of old buildings makes the environment relatively bad, and since the buildings and sites are fixed, they should be the starting point and basis of Eco-reconstruction. At first, combining the current state of architectural complex layout, we fully think of the land-form, architectural layout, afforestation and water and wind direction and so on to optimize the energy-saving effects. For example, we can make use of factors like site to shelter from or absorb solar radiation, lead or avoid prevailing wind direction so as to adjust or slow down cold wind in winter and increase or decrease temperature and humidity and so forth. 
In the Eco-reconstruction of the office building of Suzhou institute of architectural design, the local prevailing wind direction is southeast wind in summer and northwest wind in winter, then with the excavation of a basketball court in southwest and trees to be planted in the fill slope of the northwest of the site, a wind barrier which can also help shelter from sunlight and decrease the temperature in summer will be naturally formed.

\subsection{The energy-saving reconstruction of containment system}

\subsubsection{The energy-saving reconstruction of external walls}

The wall is a great contributor to the thermal losses of the whole building. Walls of majority of existing buildings have poor heat insulation performance and the heat transfer coefficient of external walls is about four folds of that of developed countries which own the similar climate with our country. And we improve the heat insulation performance hurt by structure and the thermal comfort of buildings.

(1) Thermal insulation materials

Three method can be used in thermal insulation of external walls-- external insulation, internal insulation and sandwich insulation. Materials used in insulation layer should have low thermal conductivity, low water absorption and high stability and fire proofing and corrosion protection capacity. Due to the fact that external insulation layer does not occupy the room of structural usable area and is convenient to construct, can prolong the life circle of buildings, it is widely applied. Common materials include expanded perlite, rock mine cotton and mineral wool and so on.

In a project to reconstruct a warehouse in Munich, Germany into a office, the problem to be solved in the design for Werner Herzog is to construct a simple warehouse which does not have capacity of thermal insulation, using minimal expenses. With previous brick walls reserved, double layers of film structure were added to form the double layer. This semitransparent internal heat insulation structure was a space body formed by soft and light translucent materials enclosing around. The upper part of it was heat insulation film and adjustable sunshade which was made according to the sun's angle while the middle part of it was transparent heat insulation film, the back part was adjustable solar panel. The device could make full use of natural resources and improve the heat comfort indoors.

(2) Vented double-skin facades

It is an air layer formed between previous walls and additional walls through whose local open and close, air flows within the layer so as to adjust the heat insulation capacity of walls.

It is common to add a layer on previous layer, for it is more flexible compared with internal layer, and is also able to improve previous architectural image in order to meet some certain demands on reconstructed appearance when necessary such as adding external sunshade, external balcony and double layer glass curtain wall and so on. Because external layers are limited by previous layers, attention should be paid to the direct connecting relation between old layers and new layers and the logical relation of the connection between newly added layers and other components.

External added layers form double layers which can breath freely, such as double curtain wall system. Under this system, inlets and outlets are often set in the additional external layers so that air can flow in some degree between the cavity of two layers. Common double layer curtain wall system includes integral system, corridor system and box type system.

In the project to reconstruct office buildings of Norwegian University of Science and Technology, previous buildings were office buildings of 1970s, and load-bearing structure of walls made of precast con crete and the construction of unit window were involved. The main part of reconstruction was to reduce energy consumption and utilize solar energy. An independent layer was added, fixed by steel structure, with glass type materials were added in the external layer. In the height out of sight, a photovoltaic system was integrated into the whole structure. There was a cavity whose width was about $80 \mathrm{~cm}$ between the new layer and the old layer. In added layer, there was an operable window in the previous window position and an outlet on the top, which made it a curtain wall that could breath. In winter, close outlets and inlets to get a heat insulation layer while in summer, open outlets and 
inlets to let thermal radiation be brought off in the outermost layer by cross-ventilation resulting from chimney effect (See Fig.1).
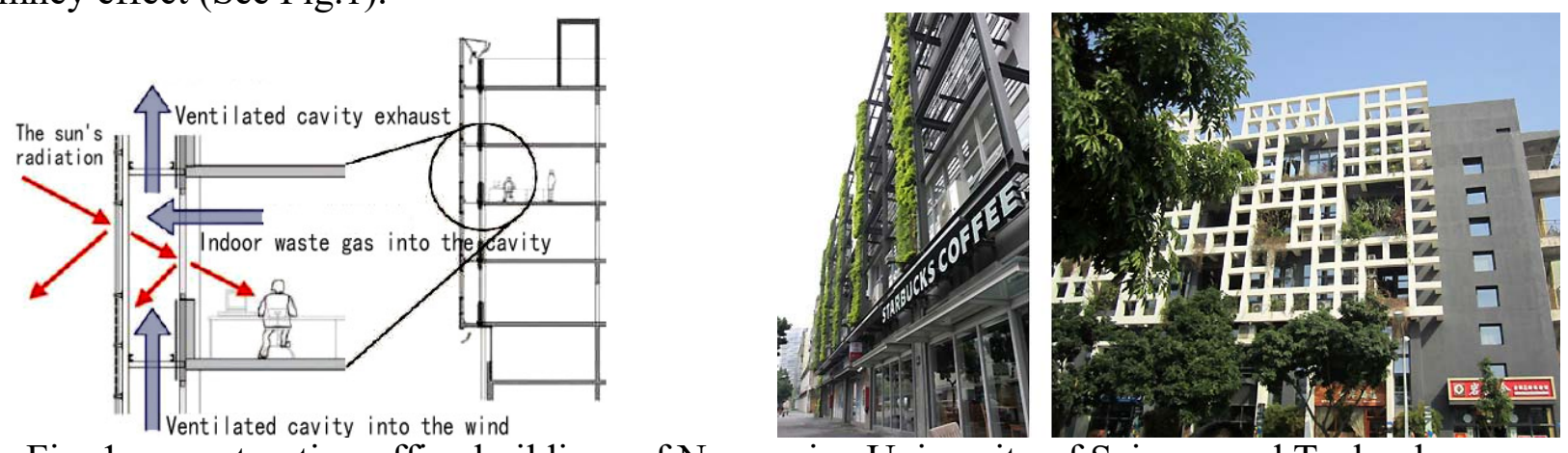

Fig. 1 reconstruction office buildings of Norwegian University of Science and Technology

Fig. 2 The west side sun-shading system of the reconstruction project of No.1 and 2 buildings at Yiku of Nanhai Sea, Shenzhen

(3) Vertical afforestation

It can improve the heat insulation capacity of walls, increase afforestation and save lands. Thus, it is a relatively economical reconstruction method. Common examples include modular type, paving type, climbing or hanging type and plate type and soon.

(4) Finishes with high reflection coefficient

Finishes with light colors are more suitable in hot regions because they can reflect more direct solar heat.

\subsubsection{Roofing energy-saving reconstruction}

Roofing thermal performance is influenced mostly by solar radiation, and its energy consumption accounts for about 22 percent of the total energy consumption of the enclosure structure. In our country, the roofs of existing buildings have poor heat insulation capacity, especially plane roof. Reconstruction strategy includes: dry laying of heat insulating roof, building heat insulating roofs on stilts and planting roofs or water surface to inflect solar radiation. The lighting effects from the roof are better than that from sideways. Also, the ventilation effects of the roof are obvious with stack effects well utilized. In the reconstruction of old buildings in Hamburg, Germany, solar power driven dynamic roofing windows were installed in roofs of buildings to introduce natural lights into house. Its intelligent system could adjust the open and close of scuttles to control ventilation according to indoor and outdoor temperature, concentration of carbon dioxide and air humidity and so on.

\subsubsection{Energy-saving reconstruction of external doors and windows}

The heat insulation capacity is worst in doors and windows, and its energy consumption is about four folds of that of external walls and accounts for approximately 40 percent of the tolat consumption of layers. Thus this part is essential to the energy-saving reconstruction of external doors and windows. The reconstruction mainly aims at door holes and the updating of components so as to modify the thermal and lighting environment indoors and outdoors and indoor ventilation. In cold regions, double hollow glass window is used; The entrance of halls should be transformed into heat insulating doors that are not only light-transmitting but also closed or additional foyers. In the reconstruction of windows, an additional layer of window can be applied in the premise of existing external windows and doors in order to avoid condensation. The distance between additional layer and existing layer should be reasonable. In regions that are hot in summer and cold in winter, heat insulating measures like using movable external sunshade and glass films can be applied in windows of east-west direction. For example, in the reconstruction of the external windows of Wenyuan Building at Tongji University, double low-e glasses were utilized to reduce heat gain in summer and heat loss in winter. In regions that are hot in summer and warm in winter, main goal is to improve the integrated sun-shading coefficient, so measures include pasting sun-shading films with low radiation and installing external sun-shading devices in windows. 


\subsubsection{Sun-shading energy-saving reconstruction}

Because of lack of consideration on the sun-shading structure in existing buildings in regions that are hot in summer, a large quantity of sun-shading energy is consumed indoors. Effective sun-shading technology can reduce the heat transmission through windows so as to improve indoor thermal comfort and reduce cold production energy consumption, improve he thermal and lighting environment indoors. Sun-shading reconstruction can be conducted in walls, windows, doors and roofs. Aiming at the relation between sun-shading components and enclosure structure, external sun-shade plays a crucial role in forming overall image of the building. Commonly, sun-shading reconstruction is combined with vertical afforestation design, such as the sun-shading system in the west in the reconstruction project in Yiku of Nanhai Sea, Shenzhen. Based on the partition of existing unit window on previous wall, sun-shading system of metal frame size and local plants was added to highlight the light feeling of metal and strong wholeness; The west side was added with sun-shading system of concrete frame and local plants. White concrete frame has a conspicuous formal sense, and the whole sun-shading system was integrated into a new side. In the system, inexpensive local silver metal-made sun-shading shutter wire mesh was applied in the form of creeper types(See Fig.2).

\subsection{Natural lighting}

It can not only save energy but also benefit people's health to reasonably utilize natural lights The most direct way of increase natural lighting in buildings is to increase the number and areas of windows, with considerations of adding high windows and skylights into deep-plan buildings at the same time. Also, it is needed to control reasonable window-wall ratio and take energy-saving measures.

\subsubsection{Lighting wells or lighting yards}

The natural lighting effects in old buildings are often poor. This condition can get better through reconstructing lighting wells and lighting yards.

\subsubsection{Optical lighting system}

Due to its function of effectively reducing day lighting power indoors, it can make full use of solar power. The principle is to gather outdoor natural lights through lighting hood and introduce lights to the system and conduct redistribution, then through the transmission in light pipe, natural lights will be effectively reflected to where lights are needed through the diffusion device at the bottom. The system consists of tree parts: light-gathering device, light-guiding device and light-diffusing device.

\subsubsection{Lighting board}

It is an economical light-gathering technology which can improve the lighting effects through the adjustment on indoor light quantity. And it is the device which can make use of light-reflecting principle to reflect lights to deeper place indoors. It demands that materials have high reflecting coefficient and will not absorb lights.

In the reconstruction of No. 3 building in Yiku, Nanhai Sea, previous building was so deep that it had to utilize artificial lighting, which led to waste of energy. The additional courtyard was like a glass box inserted in the substantial building(See Fig.3), at the meantime, the glass top of courtyard was filled with solar-power photovoltaic panels which helped better use of natural lights; And the bright metal board in the courtyard fully used skylights and natural lights to freely reflect so that there's sufficient lights indoors.

The complex sunshade in the west improved the light-gathering effects and could avoid glaring. The office rooms in the top floor was deep, so shutter belt with particular designed angle and reflecting film which had the function of reflecting lights was applied on the external wall in the south side. The top of the garage was designed as landscape pond while the bottom of it was transparent glasses which provided natural lights for the garage. 

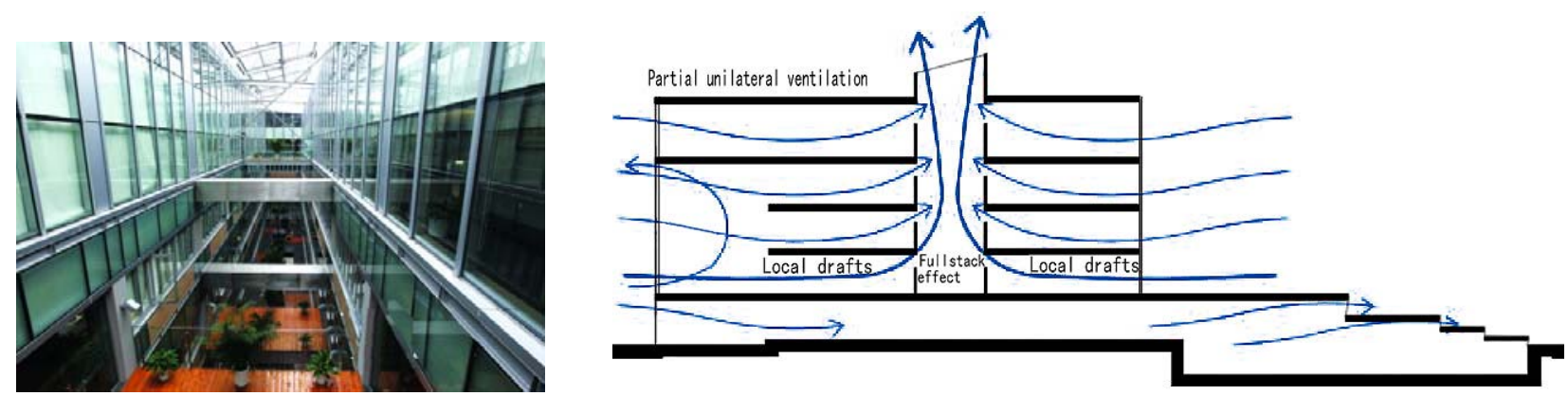

Fig. 3 Lighting of courtyard in Yiku, Nanhai Sea

Fig. 4 The analysis chart of the ventilating strategy in Yiku of Nanhai Sea

\subsection{Natural ventilation}

Natural ventilation of buildings will be affected by many factors, such as climate and surrounding environment. There are three forms of natural ventilation: those formed wind pressure such as "wind across the hall", formed by hot pressure such as "chimney effects" and formed by the combination of hot pressure and wind pressure.

\subsubsection{Optimizing the opening forms of windows}

Improve the wind environment of buildings through analyzing and adjusting the size and forms of holes by wind environment simulation software. In the reconstruction of Yifu building of Nanjing university, simulate indoors wind environment of the standard floor by software at the beginning. According to the simulating result, the indoor wind environment was relatively good in eastern rooms while the indoor wind environment was relatively poor in northwest rooms. Based on the result, optimistic strategy of opening areas of windows was put forward. In the reconstruction project of Shanghai Shendu building, external windows in the east and south sides were reconstructed into operable French window and standard green module was used in external walls to control the lighting intensity and introduce gentle and balanced lights into rooms. But in machine rooms and toilets and north, west sides of the building, traditional windows were applied to avoid winds in winter.

\subsubsection{Setting vertical ventilating wells}

As for the problem of natural ventilation where reconstruction of opening windows can not work, vertical ventilating wells can be utilized to reconstruct the indoor wind environment. Adopting the principle of chimney effects, vertical ventilating wells have diverse forms including gas well, chimney and ventilating tower and so forth. In the reconstruction of the former "Institute of Technology" of the Southeast University, the lighting and ventilating condition were poor in previous classrooms and inner corridor. The southern building was for exhibiting and training and in order to meet the demands of new functions and improve indoor wind environment, five ventilating vertical wells were added to the middle of the building, which helped the improvement of internal natural ventilating effects under the condition of small external wind pressure and guaranteed indoor heat comfort environment.

\subsubsection{Adding courtyard}

For buildings that can hardly solve the problem of natural lighting by other ways, courtyard can be added. courtyard not only is ecological core but also can enrich spaces of buildings.

In the reconstruction of the No. 3 building of Yiku in Nanhai Sea, designers made use of wind pressure so that hot wind in office rooms could flow to the courtyard which had relatively low wind pressure. In the top of the courtyard, solar-power drafting chimney were applied to employ hot pressure to promote effective ventilation, and electric shutter vents were used in the chimney which could adjust the open and close of vents according to different seasons. The chimney effects in the courtyard were totally natural ventilation. There were operable windows in all four sides to ensure natural ventilation. The reconstruction of the opening way of windows was conducted by using sliding windows whose opening areas could be quite big, which benefited ventilation. Local one-side ventilation was formed in the southern local court side. The opening space of one layer was relatively 
big, and when the windows and doors were open in the bottom courtyard, local winds which crossed the hall were readily to form. (See Fig.4).

\subsection{Passive solar-power}

It takes building itself as a heat storage device and enables the building to gather heat or reduce temperature by conducting one to another, convection and radiation via natural heat exchange method. Its used ways include direct heat-gathering type which is the most common one and is conducted directly. It makes use of south doors and windows to directly get solar radiation. Sunlight makes the surface of buildings get heat through direct shining on doors and windows. Heats are stored by convection and maintenance so as to keep a certain temperature indoors. In this way, heat efficiency is high, which results in great fluctuation of the indoor temperature. Thus it is suitable in rooms for day use. Another way is heat gathering and storing wall which can be also called as Trombe Wall. It uses solar power system indirectly. Sunlight shines through a glass cover on dark heat-storing wall to store heat, and then the system provides stable heat to indoor rooms. In this way, the indoor temperature fluctuation can be quite small and comfort degree is high. The last way is additional solar room whose principle is similar as that of Trombe Wall. It widens the air layer between glass and wall to form a usable space.

\subsection{Energy strategy}

Confronting with current energy crisis and environment crisis, developing and utilizing renewable energy is essential. Common renewable energy involves wind energy, solar power and geothermal energy and so on. Solar power can be divided into natural lighting and developed solar power. The former includes skylight design, facade lighting design and light-guide system and so on.

Use architectural materials of low producing energy consumption and are recyclable, degradable and recyclable. Approximately reserve previous structure or shell, or apply flexibly previous remnant and components to new buildings. In this way, not only costs can be reduced to minimal, but also reserve the old memories of old buildings.

\section{Conclusions}

With the gradual increase of energy-saving consciousness, Eco-reconstruction technology makes it possible for buildings to operate in a new and continuable way and will be the main strain of architectural reconstruction in the future. What's more, characteristics of low technology and low costs of passive energy-saving technology are more in accordant with the law carbon and green idea appealed in our current country. Combining practical projects, this paper concludes five commonly used passive energy-saving technologies--environment improvement, passive solar power, energy-saving reconstruction of maintenance structure, natural lighting and ventilation and green building materials, trying to establish primary method to apply passive energy-saving technology to reconstruction of buildings so as to make better use of passive energy-saving technology in practice.

\section{Acknowledgments}

Key Research Base of Humanities and Social Sciences of Sichuan Provincial Department of Education-Topic in the 2015 of Sichuan Circular Economy Research Center (GN: XHJJ-1516).

\section{References}

[1] Editorial Board of Yearbook of the reconstruction of existing buildings, Yearbook of the reconstruction of existing buildings (2012), China Architecture \& Building Press, 2013 
[2] Wang Qingqin, Tang Caoming, Guidelines of reconstruction technology of existing buildings, China Architecture \& Building Press, 2012

[3] Lin Wusheng, Wang Qingang, Yan Yongmin, Reconstruction project of No. 3 building of Yiku of Nanhai Sea, Architectural Technology, 2010,(3)

[4] Li Qun, Use nature to incubate environment, use space to construct green--Green reconstruction of existing buildings of Shanghai Shendu Building, Architectural Journal, 2013(07), 75-77

[5] Zha Jinrong, Huang Chun, The green practical exploration of reconstruction of old factory buildings--take the Eco-reconstruction of office buildings of Suzhou institute of architectural design as an example, Architectural Journal, 2011(07), 104-110 